\title{
Rupture of the stomach following mouth-to-mouth respiration
}

\author{
M. SOLOWIEJCZYK \\ M.D., F.I.C.S.
}

S. WAPNICK
M.D., F.R.C.S.

Surgical Department B, Ichilov-Municipal-Government Medical Center and

Tel Aviv University Medical School and Faculty of Continuing Medical Education, Israel

\begin{abstract}
Summary
Successful repair and survival after rupture of the stomach in a patient who received mouth-to-mouth respiration is presented. We were able to find only one report in the literature where rupture of the stomach occurred following this manoeuvre-the patient did not survive. The possible aetiological factors and measures designed to avoid this complication are discussed.
\end{abstract}

\section{Introduction}

The introduction of oxygen via a nasopharingeal tube (Hügin, 1952/3) or, accidentally, by a nasoendotracheal tube located in the oesophagus (Longobardi, Ruggles and Burgess, 1961) has on rare occasions led to sudden rupture of the stomach. Geroulanos (1972) reviewed the literature on this subject and noted that only two of twelve patients who had developed a rupture of the stomach after receiving oxygen therapy via a nasopharyngeal tube survived.

Modern methods of resuscitation following cardiac arrest include external cardiac massage and oxygen administered via an endotracheal tube. When an endotracheal tube is not available or cannot be introduced rapidly, mouth-to-mouth respiration must be instituted. The following case demonstrates one complication that may occur if this procedure is done with excessive physical effort and without due observation of measures designed to avoid it.

\section{Case report}

A.N., female, 70 years, was referred to a district hospital for excision of a small lump in the breast. The lump was excised under general anaesthesia. Halfan-hour after the completion of the anaesthetic, she became dyspnoeic, cyanosed and shortly thereafter stopped breathing. Vigorous mouth-to-mouth breathing was instituted. The blood pressure was maintained throughout this procedure. The condition of the patient improved, cyanosis disappeared and respiratory movements returned to normal. The level of consciousness improved, but she now complained of severe abdominal pain, vomited dark fluid and was found to have a pulse of $120 / \mathrm{min}$.

The patient was transferred to the Ichilov Hospital $3 \mathrm{hr}$ after the onset of respiratory arrest. She was restless, pale, sweating and examination revealed a pulse of 150/min and a blood pressure of 190/130. The abdomen was markedly distended and signs of generalized peritonitis, more accentuated in the upper abdomen, were evident. Percussion over the liver area gave a resonant note. An electrocardiogram showed ischaemic changes without any clear evidence of a recent myocardial infarction. A nasogastric tube was inserted and fresh blood containing blood clots was aspirated. A film of the erect abdomen showed free air under the diaphragm (Fig. 1). After intravenous administration of fluids, laparotomy was performed. On opening the peritoneal cavity, a large amount of gas under tension was noted. There was a small amount of free fluid in the peritoneal cavity. Examination of the stomach showed a starlike rupture, approximately $4 \mathrm{~cm}$ in length, located in the upper part of the lesser curvature, and surrounded by extensive haemorrhage (Fig. 2). There was no evidence of an underlying inflammatory or malignant ulcer. The starlike laceration was excised and the defect closed in two layers. The post-operative course was uneventful. The biopsy report of the excised lump showed that the breast tumour was an adenocarcinoma, and postoperative irradiation was given. The patient was last seen 18 months after the operation, at which time she was noted to be in good health.

\section{Discussion}

In a review of the literature, we were able to find only one similar case where there was rupture of the stomach in a patient who had received mouth-tomouth respiration (Valtonen and Hakola, 1964). Resuscitation had been unsuccessful.

We attribute the survival in our patient to early recognition of this complication and performance of 


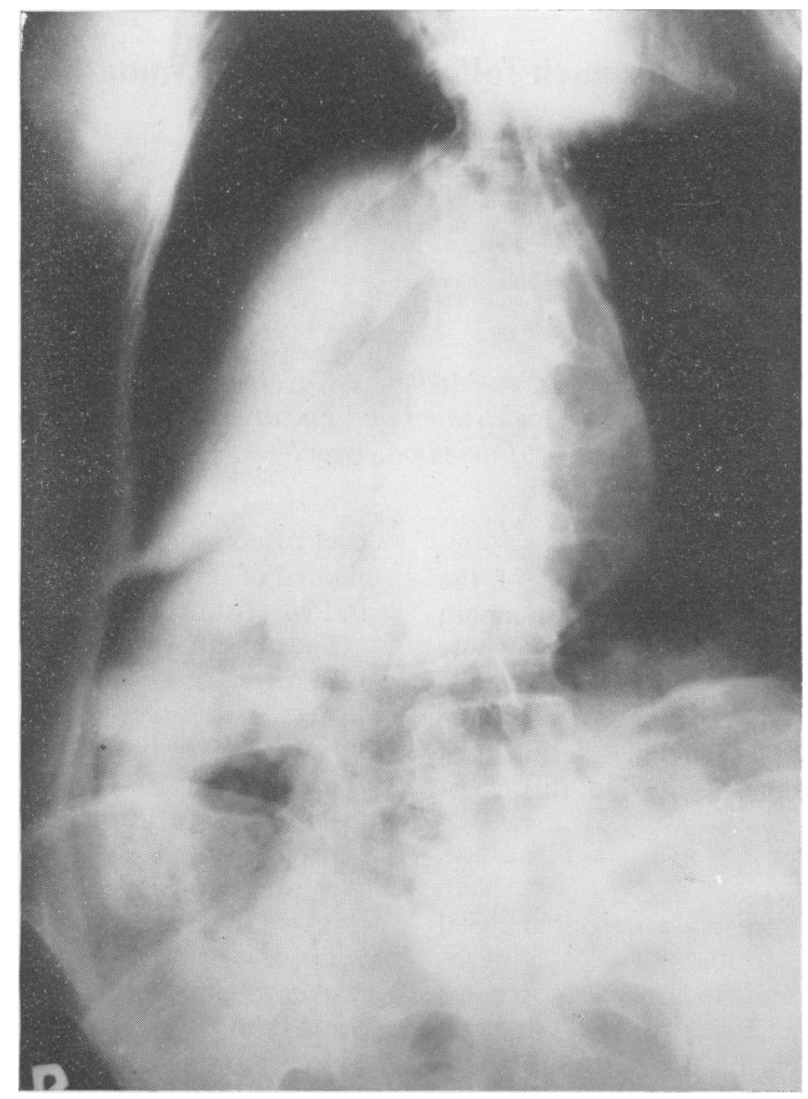

FIG. 1. Large amount of air below the diaphragm seen on film of the erect abdomen.

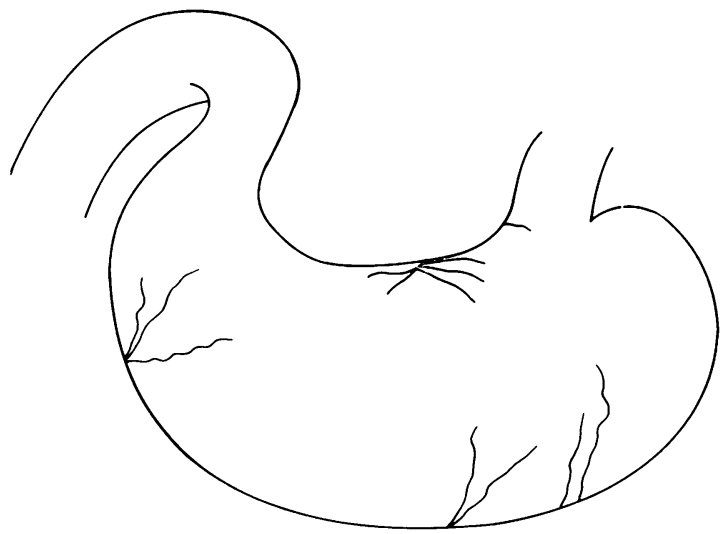

FIG. 2. Diagrammatic representation of rupture of stomach along its lesser curvature.

immediate operation. The sudden appearance of abdominal distention, pain and hypoxaemia should alert the physician to exclude this condition. A film of the erect abdomen (only meaningful if an abdominal operation has not recently been performed) must be taken to determine the presence of air under the diaphragm.

Geroulanos (1972) reviewed twelve patients who developed a rupture of the stomach following oxygen therapy administered through a nasopharyngeal tube. All the patients were female and, with one exception, above 60 years of age.

The pathogenesis of rupture of the stomach following mouth-to-mouth respiration in our patient, can be surmised to be due to the sudden rise in intragastric pressure caused by the over vigorous efforts of a powerful surgeon. Rupture of the stomach by oxygen or air is more likely to take place when ventilatory efforts are forceful, the escape of gastric contents is partly prevented by distal obstruction (Geroulanos, 1972; Makkas and Geroulanos, 1934) and when gastric dilatation alters the gastrooesophageal angle and thus prevents exit of gas into the oesophagus (Geroulanos, 1972). 

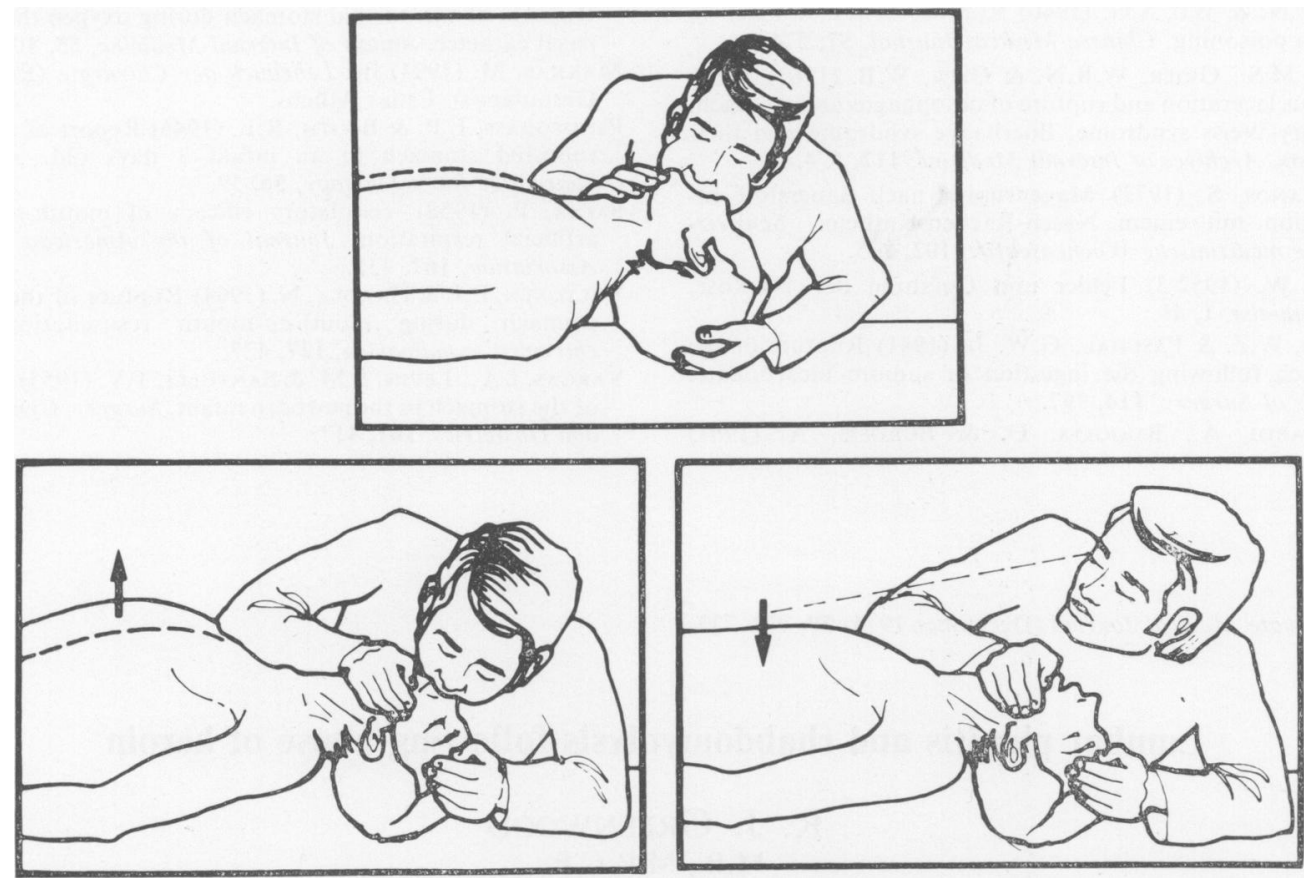

FIg. 3. Suggested method of mouth-to-mouth breathing. Upper diagram: patient's head is extended and a moderate amount of air is forced in. The lower left diagram demonstrates that during this procedure the chest wall must be examined to confirm that adequate chest expansion takes place. During expiration the abdomen is inspected to ensure that excessive distention has not taken place (lower right diagram).

Local ischaemia (Bagilo and Fattal, 1962), congenital weakness (Bruno, Grier and Ober, 1963) and the intake of sodium bicarbonate (Lemmon and Paschal, 1941) may predispose towards gastric perforation but are unlikely to have contributed to the ruptured stomach in the patients reviewed by Geroulanos (1972) and in our patient presented in this report. The stomach may rupture spontaneously in newborn infants (Pendegrass and Booth, 1946) or after oxygen administration by a nasopharyngeal tube (Vargas, Levin and Santulli, 1955). Rupture of the stomach may also occur following opium overdosage (Bien and Wu, 1940). Although we cannot determine whether or not our patient was given morphine, or any other opiate, following excision of the breast at the district hospital, its administration could explain the development of sudden respiratory arrest. The administration of opiates is known to interfere with intestinal motility and may have accentuated the sudden rise in intragastric pressure following mouth-to-mouth breathing.

Respiratory arrest is an acute emergency, requiring rapid correction. Every physician should be able to intubate the trachea, but at times he must be prepared to carry out mouth-to-mouth respiration. The measures that should be taken to prevent rupture of the stomach are outlined in the legend of Fig. 2.
Early recognition of this complication is essential; Geroulanos (1972) noted that only two of twelve patients who received oxygen therapy via a nasogastric tube survived following rupture of the stomach, and Valtonen and Hakola (1964) found three surviving patients in a review of forty-two patients who developed this complication following different forms of resuscitation.

Safar (1958) pointed out that gastric distention frequently occurred following mouth-to-mouth respiration, and he attributed its onset to failure to support the jaw and/or the excessive application of force to expand the chest during this procedure. If marked abdominal distention impairs excursion of the diaphragm, then abdominal paracenthesis must be performed to relieve the rise of intra-abdominal pressure. After the initial period of resuscitation by intravenous fluids, correction of electrolytes, acidbase imbalance and haemoglobin deficit, laparotomy, suction of the peritoneal cavity and closure of the defect are indicated.

\section{References}

Bagilo, C.M. \& FatTAL, G.A. (1962) Spontaneous rupture of the stomach in the adult. American Journal of Digestive Diseases, 7, 75. 
BIEN, W.N. \& Wu, S.G. (1940) Rupture of the stomach in opium poisoning. Chinese Medical Journal, 57, 574.

Bruno, M.S., Grier, W.R.N. \& Ober, W.B. (1963) Spontaneous laceration and rupture of oesophagus and stomach. Mallory-Weiss syndrome, Boerhaave syndrome and their variants. Archives of Internal Medicine, 112, 574.

Geroulanos, S. (1972) Magenruptur nach Sauerstoff Insufflation mit einem Nasen-Rachen-Katheter. Schweizerische medizinische Wochenschrift, 102, 205.

HügIN, W. (1952/3) Fehler und Gefahren der Narkose. Anaesthetist, 1, 46.

Lemmon, W.Z. \& Paschal, G.W. JR (1941) Rupture of the stomach following the ingestion of sodium bicarbonate. Annals of Surgery, 114, 997.

Longobardi, A., Ruggles, D. \& Burgess, A. (1961)
Rupture of the normal stomach during oxygen therapy by nasal catheter. Annals of Internal Medicine, 55, 1014.

MAKKAS, M. (1934) In: Lehrbuch der Chirurgie (Ed. by M. Geroulanos). Estia: Athens.

Pendegrass, E.P. \& Booth, R.E. (1946) Report of a case of ruptured stomach in an infant 3 days old. American Journal of Roentgenology, 56, 59.

SAFAR, P. (1958) Ventilatory efficacy of mouth-to-mouth artificial respiration. Journal of the American Medical Association, 167, 335.

VALtonen, E.J. \& HAKola, N. (1964) Rupture of the normal stomach during mouth-to-mouth resuscitation. Acta chirugica scandinavica, 127, 427.

VARGaS, L.L., LeVIN, S.M. \& Santulli, T.V. (1955) Rupture of the stomach in the newborn infant. Surgery, Gynaecology and Obstetrics, 101, 417.

\title{
Lumbar plexitis and rhabdomyolysis following abuse of heroin
}

\author{
R. J. GREENWOOD \\ M.B., M.R.C.P. \\ St Leonard's Hospital, London, N.1
}

\begin{abstract}
Summary
A young man was admitted following abuse of impure ('Chinese') heroin. He showed a number of the less common complications of heroin abuse. These are now more likely to be seen in England in view of the increasing incidence of heroin addiction.
\end{abstract}

\section{Case history}

A white man of 22 was found unconscious $24 \mathrm{hr}$ after an intravenous injection of impure heroin. He had abused a variety of drugs since 1965 including, from 1968 till 1970, heroin, but had held down a job for 5 years and avoided opiates for the last 2 years. On admission he was unconscious, responding only to painful stimuli, and pyrexial, hypotensive, and tachypnoeic. There were widespread rales in both lungs, and no focal neurological signs save an absent right ankle jerk. His pupils were normal.

Investigations showed a hyperkalaemic metabolic acidosis-plasma urea $65 \mathrm{mg} / 100 \mathrm{ml}$; potassium $7.5 \mathrm{mEq} / \mathrm{l}$; arterial pH 7.24; $\mathrm{PCO}_{2} 31 \mathrm{mmHg} ; \mathrm{Po}_{2} 80$ $\mathrm{mmHg}$. There were atypical lymphocytes and a neutrophil leucocytosis in the stained film. Serum enzymes were grossly raised-SGOT 1240 units; HBD 3000 units. Unfortunately, serum muscle

Present address: The National Hospitals for Nervous Diseases, Queen Square, London WC1N 3BG. enzymes and myoglobin levels were not measured. He was oliguric and the first urine sample was dark brown, benzidine-positive, but contained no red blood cells. Chest X-ray showed widespread pulmonary oedema, and the electrocardiogram (ECG) showed right bundle branch block with ST elevation. His hyperkalaemia was treated with intravenous calcium, insulin and glucose, and a calcium resonium enema, and his acute renal failure with intravenous frusemide and mannitol.

He was alert after $12 \mathrm{hr}$ and over the next 3 days his temperature, ECG and chest X-ray reverted to normal. He remained oliguric, his plasma urea rose to $250 \mathrm{mg} / 100 \mathrm{ml}$ after 3 days, and peritoneal dialysis was instituted for the next 7 days. High dose excretion urography showed changes compatible with acute tubular necrosis (Fry and Cattell, 1972). Four weeks after admission his creatinine clearance was normal.

The day after admission he had complained of pain in the right leg. The anterior compartment was swollen and indurated, and there was weakness of tibialis anterior, extensor hallicis longus, and extensor digitorum longus on the right. Three weeks after admission he began complaining of pain in both feet. Examination then showed weakness of the dorsiflexors of the left foot, and of flexor digitorum and the peroneal muscles on the right, in 